\title{
Valença: \\ dos caminhos de comércio à indústria
}

Théo Lobarinhas Piñeiro*

\begin{abstract}
Resumo
O artigo objetiva discutir o processo de formação e desenvolvimento da cidade de Valença, situada no Vale do Paraíba, no Rio de Janeiro, bem como a maneira como ocorreu, naquela cidade, a superação do impacto gerado pela crise da cafeicultura escravista. A formação da cidade está ligada ao comércio tropeiro, ao impulso e riqueza gerada pela expansão cafeeira, passando por rápida modernização. A crise da cafeicultura escravista atingiu, de forma diferenciada, diversos municípios do Vale do Paraíba. Em Valença, a diversificação econômica, o desenvolvimento comercial e industrial da cidade - sua ligação campo-cidade e com menor concentração fundiária que outros municípios - colaboraram para que fosse menos atingida pela crise e avançasse rapidamente para as relações capitalistas. Tal processo é o objeto de reflexão deste trabalho.
\end{abstract}

Palavras-chave: Valença (RJ); Economia Escravista; Cafeicultura; Crise do Escravismo; Indústria.

\begin{abstract}
This article discusses the foundation and development of the city of Valença, located in Paraiba Valley, Rio de Janeiro. We analyze how the city overcame the impact generated by the crisis of the coffee export economy based on slavery. The city flourishes connected to drover trade, enriched by the expansion of the coffee slave economy and going through fast modernization. The crisis of the coffee slave economy hit the cities in Paraiba Valley in different ways. Valença experienced a mild impact, quickly advancing to capitalism, given the city's economic diversification, the advanced commercial trade and industrial development, the intense citycountryside connection, and a less concentrated land structure.
\end{abstract}

Keywords: Valença (RJ); Slave Economy; Coffee Economy; Slave Economy Crisis; Industry.

\footnotetext{
* Professor do Departamento de História e do Programa de Pós-Graduação em da UFF. E-mail: theo@historia.uff.br
} 


\section{1 - A construção da região: os caminhos do ouro, o café e a escravidão}

Quem chega, de ônibus, à cidade de Valença, encontra, nas paredes da rodoviária local, uma grande pintura que nos conta, de forma sintética, porém clara, os principais elementos para entender a história da cidade.

Um enorme painel mostra aos que ali desembarcam que, dominada por indígenas até o século XVIII, a área foi sendo ocupada, a partir dos caminhos abertos, para ligar a cidade do Rio de Janeiro ao sul de Minas Gerais, o que propiciou o surgimento de sítios produtores de gêneros, logo substituídos pela lavoura cafeeira, que dinamizou a região e cuja decadência foi seguida, pouco depois, pelo surgimento de importantes atividades industriais. Neste artigo, proponho uma reflexão que, recuperando esse processo histórico, procure avaliar os diversos fatores que contribuíram para a maneira pela qual se deu a superação da crise da cafeicultura fluminense em Valença.

No início do século XIX, a região conhecida como Vale do Paraíba Fluminense era quase toda uma grande floresta virgem, sendo sua principal importância o fato de ser passagem quase obrigatória das rotas, especialmente comerciais, que ligavam o sul da Província Minas Gerais à cidade do Rio de Janeiro. Uma imensa área territorial não ocupada não é, ainda, uma região, na medida em que esta é, antes de tudo, uma construção social, produto da ação humana sobre um território, que

(...) só ganha significação quando percebida à luz de um sistema de relações sociais que articula tanto os elementos que lhe são internos quanto aqueles externos. É a partir dessa articulação, por intermédio de um jogo de identidades e oposições, que se torna possível traçar os limites da região, que muito mais do que limites meramente físicos existem enquanto limites sociais. (Mattos, 1986:24-25)

Nesse sentido, o Vale é uma construção da lavoura cafeeira, melhor dizendo, dos escravos e senhores que transformaram a floresta em um imenso cafezal. A expansão do café determinará a derrubada da mata e o surgimento da várias vilas e posteriormente ricas cidades.

Desse modo, como lembra Fridman,

(...) o povoamento da "serra acima" (...) começou com a abertura de caminhos e a instalação de postos de fiscalização. Esta marcha se fez acompanhar pela concessão de sesmarias e pelo estabelecimento de freguesias e vilas. Tal onda colonizadora iniciou-se no século XVIII como um projeto urbanístico português e continuou no século XIX, período de invenção da nação brasileira e de definição de estratégias dos novos agentes que surgiram na cena econômica, política e espacial. (Fridman, 2005)

Do início de seu cultivo nos arredores da cidade do Rio de Janeiro, as plantações de café atingem a área do Vale do Paraíba, cortada pelas passagens e caminhos que ligavam a cidade à região das minas. Ao longo do chamado Caminho Novo, que partia de Paraíba do Sul, atravessando a Serra do Mar e atingindo o Porto de Estrela, na Baía de Guanabara e que já se mostrava bem movimentada em meados do século XVIII, estabeleceram-se pousadas para as tropas e ranchos e permitiram posteriormente a ocupação maciça do território (Stein, 1961:9-11).

A conquista desse território liga-se também ao declínio da mineração, quando antigos proprietários da exploração dos metais preciosos - levando seus escravos - deixaram a região à procura de outras atividades, estabelecendo-se às margens dos antigos caminhos existentes, explorando a agricultura, de início, para gêneros de subsistência e, depois, com as plantações de café. (Machado, 1993:21)

Cabe ressaltar que, além da crise da mineração, a mudança no estatuto colônia - com a transferência da capital do império português para o Rio de Janeiro - e a política de ocupação de terras, empreendida pela monarquia lusitana recém-instalada, que procuravam criar uma 
base de sustentação, nos trópicos, para o trono, com uma grande distribuição de sesmarias nas áreas próximas à Corte, também muito contribuíram para tal ocupação, como atestam diversos estrangeiros que estiveram no Brasil no período (Leithold e Rango, 1960; Spix e Martius, 1975; Ferrez, 1978). Tal processo foi constatado por contemporâneos, como registra o ilustre viajante, que percorreu diversas áreas do Brasil entre 1816 e 1822, ao observar que

Depois que as minas de ouro começaram a se esgotar e a liberdade de comércio passou a dar maior valor aos produtos coloniais, os chefes de família voltaram as vistas para a agricultura e se Poe esperar ver multiplicaremse, dentro em breve, os habitantes nas vastas matas que margeiam a parte dos caminhos de Vila Rica próximas do Rio de Janeiro (...) (Saint Hilaire, 1975:40)

Outro ponto importante a ser destacado é a relação já existente entre a cidade do Rio de Janeiro e Minas Gerais, passando pelo Vale do Paraíba, construída durante a exploração aurífera, em cujas rotas passavam ouro e gêneros alimentícios de Minas para o Rio e, no sentido inverso, escravos e produtos vindos da Europa para os centros mineradores. Mas transitavam também os tropeiros e os recursos monetários, que foram de grande valia na ocupação do Vale, com o estabelecimento de pequenas propriedades e pouso para as tropas de mulas. Ali se estabeleceram ainda pequenos engenhos e, depois, os primeiros cafezais (Lenharo, 1979:29-32; Linhares, 1979).

Se tal relacionamento entre as duas regiões proporciona condições históricas para a formação do Vale como grande produtor de café, devemos lembrar que

(...) os recursos originários das minas e do setor de subsistência mercantil foram fundamentais na formação dos primeiros cafezais. Esses fatores internos aliaram-se à conjuntura internacional, favorável às exportações agrícolas brasileiras (...) O mercado externo, mais uma vez, agiu como o grande impulsionador da estrutura escravista colonial, base da lavoura cafeeira. (Machado, 1993:22)

A expansão do café transformou vilas em cidades, além de criar outras. A partir do ouro verde, surgem ou se afirmam localidades como Vassouras, Valença, Barra Mansa, Paraíba do Sul, Barra do Piraí, Resende e Cantagalo. O avanço das plantações e o surgimento/ crescimento das cidades também estão ligados à constituição de uma rede de estradas que possibilitaram a melhor ocupação do território, estabelecendo melhor o domínio do Rio de Janeiro sobre as demais áreas. Ocupar, povoar, produzir riquezas e consolidar o controle, tudo isto está relacionado à política empreendida pelo governo joanino, razão pela qual

Preocupou-se a Corte em abrir estradas e, fato quase inédito, melhorar as comunicações entre as capitanias e favorecer o povoamento. Tinham como fé obsessiva aproveitar as riquezas. Precisavam incrementar o comércio e movimentar meios de comunicação e transporte (...) As tradições de colonização portuguesa e o afã de integração e conquistas dos recursos naturais delineavam a imagem do governo central forte, necessário para neutralizar os conflitos da sociedade e as forças de desagregação internas. (Oliveira, 2001:101)

O início da ligação entre Minas Gerais e Rio de Janeiro tem como motivação principal ligar a área produtora de ouro e o porto, por onde a riqueza deveria fluir para a Europa, uma vez que

O ouro era o objetivo do homem branco, que demandava a longínqua Mantiqueira. Em meio às duras jornadas na Serra do Mar, o desbravador estrangeiro não se desanimava ante as impressionantes condições geográficas do terreno palmilhado e intensificava a devastação das florestas no Vale do Paraíba. (Iorio, 1953:22)

Mais tarde, os interesses mercantis começaram a se impor. Assim, ao Caminho Velho, ligando Guaratinguetá a Parati e daí ao Rio de Janeiro, bem como ao Caminho Novo, ambos muito antigos, vão se juntar, em princípios do século XIX, a Estrada do Comércio - aberta em 
1813 e concluída em 1817 - e a da Polícia - concluída em 1820 - , estabelecendo uma ligação mais rápida entre Minas e Rio de Janeiro (Stein, 1961:11).

A Estrada do Comércio passava pelo Vale, em Vassouras, de um lado, e em Pati do Alferes, do outro, levando mercadorias e pessoas ao Porto do Comércio, no Rio Paraíba do Sul, bem como ao Porto dos Índios, no Rio Preto. Já a Estrada da Polícia tinha o traçado da anterior, até Iguaçu, de onde seguia por Sacra Família, Vassouras, atingindo Valença até o Presídio do Rio Preto (Lenharo, 1979:60-62).

Tradicionalmente conhecida como a estrada das boiadas, a Estrada da Polícia, assim como sua congênere, a Estrada do Comércio, constituíram-se em agentes eficazes de povoamento, valorização da terra, concentração da mesma e irradiação da economia cafeeira a ponto de, posteriormente, serem identificadas como estrada de café. (Lenharo, 1979:61)

Se os caminhos eram construídos pelos governantes, sua manutenção ficou, de fato, a cabo dos proprietários da região em construção, pois, como observou ainda aquele mesmo viajante,

(...) são os particulares, que têm propriedade às margens das estradas, que se obrigam a desembaraçá-las dos galhos de árvores que podem prejudicar o trânsito e fazer os consertos necessários para tornar menos impraticáveis os trechos lamacentos (...). (Saint Hilaire, 1975:42)

Esses proprietários são também responsáveis pela efetiva ocupação territorial, em bases econômicas, expulsando antigos pequenos posseiros e os índios da região. Os índios foram sendo destruídos pelas doenças e pela força (Machado, 1993:28-29).

Os pioneiros brancos na região possuíam poucos recursos e visavam ocupar a terra para subsistência. Chegavam, levantavam uma construção rústica, demarcavam um pequeno lote e desenvolviam pequenas roças. Com o início da expansão do café, houve conflitos entre esses e os novos donos, beneficiados pela Coroa portuguesa, ou pela força, sendo, em sua maioria, os pequenos posseiros expulsos, como constatou, mais uma vez, nosso arguto viajante:

(...) os pobres que não podem ter títulos, estabelecem-se nos terrenos que sabem não ter dono. Plantam, constroem pequenas casas, criam galinhas e quando menos esperam aparece-lhes um homem rico, com o título que recebeu na véspera, expulsa-os e aproveita o fruto de seu trabalho. (Saint Hilaire, 1974:23-24)

A chegada de homens ricos começou a afastar os antigos posseiros, gerando conflitos, às vezes judiciais, às vezes diretos, com o emprego da força. Em 1817, o governo joanino estabeleceu que a propriedade só seria reconhecida quando amparada em títulos, o que não diminuiu os embates e a apropriação das terras pelos poderosos, em que pese a grande resistência dos pequenos posseiros (Muniz, 1979).

Os novos proprietários não vieram somente com a vontade de empreender uma nova atividade. Traziam consigo os homens que trabalhariam a terra e transformariam a região: os escravos.

\section{2 - A Valença escravista}

A cidade de Nossa Senhora da Glória de Valença surge no local de um aldeamento indígena, tendo sido fundada em 1803 pelo fazendeiro José Rodrigues da Cruz, oriundo da região de Ubá, em Minas Gerais (Iorio, 1953), que dominou os índios coroados. A vila rapidamente 
cresceu e, em 1814, possuía 119 fogos e 900 adultos, sendo elevada à categoria de vila em 1823 (Lamego, 1963:171).

A escolha do local, pelos fundadores de Valença, não foi aleatória. O centro urbano foi instalado em uma posição privilegiada, no ponto em que as duas principais vias de comércio que atravessavam a região se encontravam - a Estrada do Comércio e a Estrada da Polícia tornando-se ponto de parada das tropas que faziam a ligação entre o sul de Minas Gerais e o Rio de Janeiro, o que, sem dúvida, muito contribuirá para acelerar o processo de crescimento econômico da região.

A ocupação da região está intimamente ligada a esses caminhos, como já foi visto. Entretanto, antes mesmo de suas aberturas, a Coroa portuguesa havia iniciado a doação de sesmarias na região, respectivamente em 1771, 1793 e 1797, sendo a primeira, que recebeu o nome de Santa Mônica e de grande extensão, doada ao Marquês de Baependi; a segunda, com cerca de meia légua de testada, coube ao futuro Conde de Baependi e a terceira, também de grande extensão, ao capitão João Pinheiro de Souza, casado com Izabel Maria da Visitação, da família Werneck, que seria futuramente a maior proprietária de terras na área (Iorio, 1953).

Entretanto, é a partir da expansão cafeeira no Vale do Paraíba que Valença irá crescer e afirmar-se como centro importante, sendo elevada à categoria de cidade em 1857 e à sede do município em 1872.

A atividade comercial da cidade será muito importante para a ocupação e o crescimento da região, especialmente pela íntima ligação entre tropeiros e proprietários de terra e escravos, muitos oriundos do comércio de tropa e que investiram seus recursos na propriedade fundiária e no processo produtivo (Lenharo, 1979).

A época do café marca o esplendor do Vale do Paraíba; embalada pela onda verde, podemos constatar o grande acúmulo da riqueza - tanto da esfera da produção, como na da circulação - com o novo produto brasileiro integrado às linhas internacionais do comércio (Silva, 1984; Furtado, 1976; Stein, 1961; Machado, 1993).

O café do Vale é o café do braço escravo, produzindo uma sociedade que tem a sua lógica determinada pela escravidão, com grande acúmulo de riqueza, criando em Valença uma opulência que, na região, só foi suplantada por Vassouras, o principal município cafeeiro do século XIX. Como as demais cidades do café surgidas no Vale do Paraíba Fluminense, Valença tem sua vida econômica e social imbricada com a atividade agrária e comercial. A riqueza gerada pela produção cafeeira criou uma sociedade aristocrática, porque escravista, com estreitas relações com a Corte, situada no Rio de Janeiro.

A Tabela 1 demonstra claramente o crescimento da riqueza, na cidade, a partir da arrecadação municipal.

Tabela 1

Arrecadação da Coletoria Municipal de Valença - 1840-1890 (convertida em cruzeiros)

\begin{tabular}{c|c|c|c|c|c|c}
\hline Ano & 1840 & 1850 & 1860 & 1870 & 1880 \\
\hline Cruzeiros & 7.000 & 10.031 & 15.200 & 24.600 & 45.339 \\
\hline
\end{tabular}

A área urbana não poderia ser passiva a toda essa riqueza; o processo de modernização da cidade é marcante. Além de armazéns gerais, construídos para receber e guardar o café a ser enviado ao Rio de Janeiro, uma rede de infraestrutura de serviços básicos é rapidamente 
construída, como esgoto e distribuição de água. Encontramos também colégios, casas comerciais, serviços de profissionais liberais - especialmente médicos e advogados -, bem como um moderno teatro, construído para apresentação de companhias vindas da Corte.

Para compreender como a grande riqueza gerada pela exploração escravista da cafeicultura impulsiona também a economia urbana, é necessário que se retenha a lógica e o funcionamento da reprodução escravista, embora não seja objetivo deste trabalho e já muito se tenha escrito sobre o assunto (Piñeiro, 2002; Gorender, 1978, Fragoso, 1983).

Grosso modo, devemos reter que a reprodução escravista tem duas faces, ou melhor, dois polos de realização. No setor produtivo agrícola, ela se caracteriza - em sua forma ampliada - no que Emilio Sereni denominou de reprodução extensiva, ou seja

(...) aquela categoria [que] diria respeito ao movimento em que há uma repetição de um mesmo processo de produção, sem uma modificação técnica, sendo este realizado sobre uma área (territorial, ou eventualmente, econômica) mais extensa que a originária. (Sereni, 1974:50)

A aquisição de escravos é, como já muito estudado, fundamental para a continuidade do regime escravista, sendo ainda o ponto de interseção entre a reprodução simples e a reprodução ampliada do escravismo colonial, notadamente porque, como já consagrado na historiografia, a expansão da produção escravista necessita a continuada incorporação de dois fatores de produção: terras e escravos, significando, como lembrou Fragoso, "momentos" diferentes de um mesmo processo.

Ao dividir a reprodução escravista colonial em dois momentos, João Fragoso pretende explicar que a mesma se dá não só pelos pressupostos da reprodução simples, mas também pela incorporação constante de força de trabalho e terras, e a transformação das matas em cafezais, fazendo a distinção entre a reprodução simples como aquela que incorporava mais terras e a reprodução ampliada (extensiva), aquela que incorpora, não só mais terras, como também mais escravos - e ao mesmo tempo (Fragoso, 1983, especialmente o capítulo "A Reprodução Propriamente Dita”).

A necessidade de sempre adquirir novos escravos e a profunda ligação entre a produção escravista e o mercado ${ }^{1}$ ajudam a revelar a outra face da reprodução escravista, seja no que se refere ao financiamento, seja no relativo à comercialização da produção. Como mostra Gorender, independentemente de se tratar da montagem do empreendimento ou de sua continuidade,

(...) o plantador continuava a carecer de sucessivos financiamentos, seja para ampliar os recursos produtivos, seja para cobrir déficits de anos maus. O mercador cumpria a função de financiamento e a vinculava rotineiramente à da circulação, isto é, à comercialização das safras (...). (Gorender, 1978:492)

Esta vinculação entre o plantador escravista e o negociante - aqui compreendido, conceitualmente, como o proprietário de capitais que atua na esfera da circulação, do financiamento, investe no tráfico de escravos e mesmo no abastecimento, controlando os setoreschave da economia urbana e, pela sua posição no fornecimento da mão de obra, influindo diretamente na economia escravista colonial - responsável pelo financiamento da produção (escravos, implementos agrícolas etc), bem como de outras necessidades do plantador, não necessariamente ligadas à produção propriamente dita, permite que apreendamos melhor a outra face da reprodução escravista (sobre o conceito de negociante e também sobre reprodução escravista, ver Piñeiro, 2014). 
A maneira pela qual se faz o financiamento e a comercialização da produção escravista reforça, a cada momento do processo, a intermediação comercial-financeira, completando um circuito financiamento-produção-comercialização (sobre o conceito de intermediação comercial-financeira e suas implicações sobre a economia baseada na agroexportação, ver Oliveira, 1980). Tal processo reitera, no caso do modo de produção escravista colonial, a subsunção formal do trabalho ao capital, que implica a transferência de renda da esfera da produção para a da circulação (Marx, 1978:56-57), o que, no caso, advém dos lucros auferidos sobre o financiamento concedido ao plantador, bem como da comercialização da safra, pelos negociantes, o que significa que, no processo de reprodução do escravismo colonial (Ferreira, 1977), o setor produtivo escravista expressa sua acumulação em terras e escravos, enquanto o setor de financiamento e comercialização concentra, cada vez mais, os recursos monetários, ora se apresentando sob a forma de capital comercial, ora se apresentando como capital usurário e posteriormente bancário (Andrade e Levy, 1979).

Neste sentido é que se entende a relação entre a produção agrária para exportação - e a grande riqueza que o café gerava - e o desenvolvimento do espaço urbano. A transferência de parcela considerável da riqueza do setor produtivo escravista para a esfera da circulaçãofinanciamento possibilita o surgimento de uma grande atividade urbana, que não se limita apenas à economia cafeeira, mas a tem como grande impulsionadora. Por tal razão, pode constatar um memorialista da região que Valença havia se transformado em uma das cidades mais importantes da província fluminense, sendo “(...) seu comércio animadíssimo, possuindo (...) casas importantes (...), cujos armazéns recebiam, anualmente, milhares de arrobas de café do município (...)” (Ferreira, 1978:17).

O grande crescimento econômico e a importância política da cidade de Valença se traduziram também na reorganização do seu espaço urbano, sua "modernização". A velha vila, centro da área rural, foi sendo transformada, com a riqueza gerada pelo café e pela atividade comercial. Algumas ruas foram alargadas, praças e jardins foram construídos no centro, tendo sido contratado o arquiteto francês Glaziou para dar nova paisagem à cidade (Iorio, 1953).

Em 1883, havia cerca de 26 mil escravos em Valença - incluindo as zonas urbana e rural do município - estimando-se a população local em cerca de 33 mil habitantes (Lamego, 1963:193). Nesse mesmo ano, a produção urbana já contava com uma manufatura de carros e trolys, o que demonstra, mesmo durante o período escravista, a diversificação e o crescimento da cidade (Riebeyrolles, 1980:53).

$\mathrm{Na}$ área rural, dominada pelo café, pode ser encontrado também um grande número de pequenas e médias propriedades, que se ocupam da produção de gêneros para o abastecimento da cidade. Nos caminhos que conduzem ao núcleo urbano, da mesma forma que em outras urbis da região, há casas comerciais, ainda que modestas, atestando a importância da produção dessas pequenas unidades (Muniz, 1979).

A estrada de ferro, com a inauguração do primeiro ramal da Companhia União Valenciana, em 18 de maio de 1871, dinamiza ainda mais a região, interligando-a melhor com o Rio de Janeiro, escoando a produção para o porto da capital do Império e aumentando a circulação de mercadorias e pessoas. A ferrovia foi muito importante, não só pela ligação estabelecida entre a cidade e o porto da Corte, como também porque iria possibilitar, mais tarde, o crescimento de outras atividades, uma vez que “(...) as estradas de ferro eram tão essenciais ao desenvolvimento econômico quanto o fornecimento de energia” (Dean, 1997:225).

Tendo em vista a importância do núcleo urbano da região, é que não podemos concordar com a simplicidade da avaliação que entende ser Valença “(...) mais inclinada a uma vida 
predominantemente agrária, à ufania do isolamento solarengo entre os opulentos domínios do café" (Lamego, 1963:171).

É verdade que a cidade deve ser entendida como o núcleo urbano de uma região agrária. Entretanto, devemos compreender que, apesar da sustentação econômica advir da produção cafeeira, o grande luxo existente na cidade, expressando uma situação de opulência e modernidade, atestando o seu apogeu, tal fato se deve à relação intrínseca entre o mundo rural e o urbano, que repousa na lógica da reprodução escravista, implicando, na esfera política, a aliança entre frações de classes proprietárias - negociantes e proprietários de terras e escravos (Piñeiro, 2014) -, bem como a concentração de recursos monetários na esfera da circulação e que será importante para o desenvolvimento de outras atividades no período pós-abolição.

\section{3 - Valença pós-abolição}

O fim da exploração do trabalho escravo viria alterar completamente este quadro, com um declínio da lavoura cafeeira, não só pelo fim do cativeiro, mas também pelo desgaste do solo, tendo em vista a forma predatória da produção escravista. Os antigos escravos foram substituídos por trabalhadores livres, nas mais diversas relações de trabalho - parceira, meação etc (Gorender, s/d:45-46) - e, na região de Valença, podemos constatar a chegada de alguns colonos, o que lhe daria uma qualidade distinta de outras cidades do Vale, embora o trabalho na denominada "colônia" fosse desempenhado, ao mesmo tempo, por ex-escravos e trabalhadores livres, trazidos de outras regiões:

A colônia consta de 64 famílias de libertos, uma de brasileiros nascidos livres, e duas de portugueses, que trabalhão pela retribuição proporcional aos alqueires que colhem ao lote do qual tratão, como na fazenda do Córrego de uma turma de 35 jornaleiros mineiros, dependentes de um chefe que, único, entende-se como administrador e recebe $3 \$$ a secco por cada dia inteiro de trabalho de cada homem e proporcionalmente pelas frações de dia; de outra turma de 15 trabalhadores também com chefe que para isto recebe $1 \$$ por cada alqueire de que colhem. Além disso, há 65 pessoas pagas mensalmente, empregadas na fazenda, isto é, serradores empregados, empregados de terreiro, carreiros, carapinas, campeiros, cozinheiros, cocheiros, empregados de sova, pedreiros, empregados do engenho, tropeiros etc. (Zerrity, 1895)2

É importante ressaltar, como já foi visto, que, durante o período escravista, a atividade comercial foi muito importante para a economia e a sociedade valenciana, destacandose empresas mercantis, tais como Jeronymo Macedo \& Ferreira, Pentagna \& Sampaio, Faria \& Pacheco, Antonio Rodrigues de Oliveira e outras, tendo esta última firmado-se na região e atravessado, pelo menos, as três primeiras décadas do século XX, apesar do grande processo de concentração de empresas, que se seguiu ao fim do regime escravista e à inflação gerada pelo Encilhamento (Damasceno Ferreira, 1978:21).

Se, por um lado, a região do Vale do Paraíba sentiu o fim do trabalho escravo, pois, como lembra Stein, os senhores se agarraram à escravidão até os últimos dias, a ponto de, em 20 de março de 1888, agredirem um fazendeiro que propunha que se libertassem os escravos antes da medida oficial, não houve a catástrofe que os defensores da continuidade do trabalho servil anunciavam, caso se extinguisse rapidamente o cativeiro (Stein, 1961:305-306). 
Ainda em 1888, foi construída uma rede telefônica, custeada pelo comerciante Antonio Fernandes Netto, que nela investiu 5:605\$000, que servia à cidade e a interligava a outros municípios, utilizando, para instalação, o espaço da rede ferroviária (Ferreira, 1978:3).

Além da grande concentração de capital comercial, que em breve começaria a ser investido também na indústria, como veremos, um importante fator do desenvolvimento fabril do município foi o apoio que tal atividade recebeu da Prefeitura e da Câmara Municipal, o que atesta que o poder, na cidade, era exercido não apenas pelos proprietários de terras, como também pelos que se dedicavam a explorar a economia urbana, reiterando nossa visão do Estado brasileiro, desde o império, que tem por base a aliança entre frações das classes proprietárias, tanto da agricultura, como do grande comércio e financiamento (Piñeiro, 2014).

O primeiro passo nesse sentido pode ser apreendido pela decisão da Câmara Municipal, em 1891, que cedeu uma área da cidade para instalação de uma fábrica (Ferraz, 2005), e que, em 1903, buscou incentivar novos empreendimentos, concedendo a Avelino Augusto Guimarães isenção de impostos, visando à organização de uma fábrica de meias e camisas de meia (Damasceno Ferreira, 1978:314).

Dois anos depois, Antonio José Soares, um major reformado, fundou a Fábrica de Cigarros Santo Antônio (Damasceno Ferreira, 1978:28). No mesmo ano, temos a inauguração da primeira indústria têxtil da cidade, a Companhia Industrial de Valença, que visava a fabricação de tecidos de algodão, um empreendimento que apontaria para o futuro industrial da cidade, bem como para um aspecto importante para o desenvolvimento da indústria na região, a saber, a associação dos capitais de Valença com os oriundos da região sul de Minas Gerais. A empresa era uma sociedade entre o negociante valenciano José Siqueira e Silva da Fonseca e o também homem de negócios Benjamim Ferreira Guimarães, de Bom Sucesso de Minas Gerais, que atraíram novos sócios e receberam, da Câmara Municipal, além de um grande edifício abandonado, que se localizava em frente da estação ferroviária, diversas outras vantagens fiscais (Guimarães, 1977:37).

Na década seguinte, a cidade recebeu as linhas do telégrafo e, em 1913, a indústria local se ampliava, com a fundação da Companhia de Rendas e Tiras Bordadas Dr. Frontin, com o considerável capital de 400:000\$000 (Damasceno Ferreira, 1978:31).

O crescimento industrial da cidade gerou, por consequência, o aumento do número de operários, que logo buscaram se organizar, sendo criada, em 1920, a Sociedade União Operária Valenciana, que se mostrou bastante ativa na defesa dos interesses da classe trabalhadora.

Uma questão importante para entender as transformações na região remete à política econômica adotada pelo governo fluminense, principalmente a partir da gestão de Nilo Peçanha à frente do Executivo estadual, visando uma diversificação agrícola para fazer frente à crise da cafeicultura.

No que se refere a Valença, além da política de diversificação já apontada, foi fundamental também a melhoria do sistema de transporte ferroviário e sua ligação com as demais cidades, o que se deu com a encampação, pelo governo federal, durante a presidência de Nilo Peçanha, da estrada de ferro União Valenciana (Damasceno Ferreira, 1978:29).

Foi a execução de tal política de diversificação que ajudou, em muitos lugares, a superação de um estado crítico a que havia chegado a lavoura cafeeira, com a introdução de outras atividades econômicas (Mendonça, 1977). Isto não quer dizer que o café deixou de ser, de imediato, o principal produto, e sim, que gradativamente foi cedendo lugar a outras culturas - uma vez que a produção passou de 5.768 .555 pés (em 256 propriedades), em 1920, para 3.385.300 pés (em 37 propriedades), em 1940/42 (Departamento Nacional do Café, apud Iorio, 1953) -, como se vê na Tabela 2. 
Tabela 2

Produção em Valença - 1937-1940

(valores convertidos em cruzeiros)

\begin{tabular}{c|c|c|c|c|c|c}
\hline ANOS/PRODUTOS & \multicolumn{2}{|c|}{ AGUARDENTE } & \multicolumn{2}{c}{ MANTEIGA } & \multicolumn{2}{c}{ QUEIJO } \\
\hline & LITROS & VALOR & KG & VALOR & KG \\
\hline 1937 & 33.028 & 26.422, & 122.286 & 611.430, & 226.481 & 1.358 .866$, \\
\hline 1938 & 76.412 & 137.541, & 256.928 & 1.798 .496$, & 362.115 & 2.896 .920$, \\
\hline 1939 & 63.862 & 108.565, & 235.397 & 1.294 .683$, & 314.467 & 1.415 .101 \\
\hline 1940 & 87.560 & 157.608, & 263.733 & 2.109 .864 & 385.293 & 2.697 .051 \\
\hline
\end{tabular}

Fonte: Anuário Geográfico do Rio de Janeiro (1951), apud Leoni lorio. Valença de ontem e hoje. Op. cit.

Consoante com tal diversificação, o município se torna o maior criador de gado do Vale do Paraíba Fluminense, com rebanhos que, em meados da década de 1930, atingem 39.047 ovinos e 11.038 suínos (Iorio, 1953). Ao agregarmos os números apresentados na tabela anterior, bem como os relativos aos rebanhos existentes, com os referentes à distribuição demográfica, podemos refletir sobre o impacto das transformações ocorridas do município.

Tabela 3

População de Valença

\begin{tabular}{c|c|c|c}
\hline ANOS/DISTRIBUIÇÃO & POPULAÇÃO TOTAL & POPULAÇÃO URBANA & POPULAÇÃO RURAL \\
\hline 1892 & 33.263 & 6.175 & 27.088 \\
\hline 1920 & 41.389 & 13.020 & 28.369 \\
\hline 1940 & 37.032 & 12.912 & 24.120 \\
\hline
\end{tabular}

Fonte: Alberto Lamego. 0 Homem e a serra. Op. cit.

Os números acima demonstram, por um lado, um certo êxodo após 1930, o que certamente é explicado pela atração de áreas mais industrializadas, especialmente tendo em vista a política econômica desenvolvida no período Vargas, cuja discussão foge aos objetivos deste trabalho (sobre o assunto, ver: Mendonça, 1986; Ianni, 1977; Villela e Suzigan, 1975). Por outro lado, é significativo que a população urbana tenha crescido, em termos proporcionais, sobre a rural - 18,56\%, em 1892, para 34,87\%, em 1940 - o que certamente está ligado à instalação, na cidade, de indústrias (têxtil, bebidas, água mineral e macarrão), produção esta que novamente interliga Valença ao circuito de trocas regional e nacional (Iorio, 1953).

A tradicional ligação da cidade de Valença com a região do sul de Minas, bem como com a cidade do Rio de Janeiro, foi muito importante para que pudesse avançar na diversificação agrícola, como demonstram os dados anteriores, ao que se soma ainda a produção de fumo, e principalmente na instalação de um parque industrial, seja pelo acesso a mercados consumidores e áreas fornecedoras de matérias primas, seja, em especial, pelos capitais gerados no comércio que puderam ser investidos na cidade.

Nesse contexto, ganha relevo o desenvolvimento da indústria têxtil, com destaque para a Cia. Progresso de Valença Fiação e Tecelagem, importante empresa da cidade, que abastecia o mercado nacional. $\mathrm{O}$ crescimento da sociedade pode ser constatado pelos dados a seguir. 
Tabela 4

Produção Anual e $n^{\circ}$ de Operários da Cia. Progresso de Valença

\begin{tabular}{c|c|c|c}
\hline \multirow{2}{*}{ ANO } & \multirow{2}{*}{ No OPERÁRIOS } & \multicolumn{2}{|c}{ PRODUÇÃO ANUAL } \\
\cline { 3 - 4 } & 996 & METROS & VALOR (Cr\$) \\
\hline 1930 & 1.081 & 6.260 .442 & 6.985 .089$, \\
\hline 1933 & 1.146 & 8.074 .019 & 8.698 .069$, \\
\hline 1935 & 2.110 & 8.701 .361 & 10.132 .650$, \\
\hline 1938 & 1.171 & 8.129 .646 & 8.876 .500$, \\
\hline 1940 & & 7.520 .095 & $9.580,140$, \\
\hline
\end{tabular}

Fonte: Anuário Geográfico do Rio de Janeiro (1951), apud Leoni lorio. Valença de ontem e hoje. Op. cit.

Esses números nos permitem apreender que a empresa, apesar de uma leve queda, mantinha-se em desenvolvimento, o que ajudou a fazer crescer também a cidade. Por sinal, Valença vê crescer também o seu setor urbano, com o estabelecimento de mais casas comerciais, expansão que se atesta pelo crescimento da arrecadação, na década de 1930, embora houvesse oscilações, diante das incertezas do período, o que pode ser constatado pelos dados da Tabela 5, lembrando que a arrecadação estadual, à época, incidia principalmente sobre a circulação de mercadorias enquanto a municipal sobre a propriedade urbana e a prestação de serviços.

Tabela 5

Arrecadação Municipal e Estadual no Município de Valença (RJ)

\begin{tabular}{c|c|c}
\hline ANO & ARRECAÇÃ0 MUNICIPAL (Cr\$) & ARRECADAÇÃ0 ESTADUAL (Cr\$) \\
\hline 1930 & 493.513, & 398.793, \\
\hline 1933 & 427.568, & 533.948, \\
\hline 1935 & 375.632, & 534.089, \\
\hline 1937 & 469.036, & 643.657, \\
\hline 1939 & 634.071, & 1.041 .424$, \\
\hline
\end{tabular}

Fonte: Anuário Geográfico do Rio de Janeiro (1951), apud Leoni lorio. Valença de ontem e hoje. Op. cit.

Os números acima informam que a arrecadação estadual cresceu quase $200 \%$ no período, enquanto a municipal pouco menos que 50\%, atestando o crescimento do mercado local, o que só foi possível devido ao desenvolvimento das atividades industriais na cidade.

\section{Conclusão}

Podemos notar que o crescimento da atividade urbana sobre a rural, no Município de Valença, no pós-abolição, se baseia em três eixos importantes, além da grande transformação nas relações de produção.

O primeiro liga-se à diversificação econômica na região, impulsionada, de um lado, pela política empreendida pelo governo fluminense e, de outro, pelo afluxo dos capitais na região, bem como o seu deslocamento do comércio para a produção. O segundo eixo, embora intimamente ligado ao primeiro, relaciona-se com o aumento do mercado consumidor na própria cidade, a partir da instalação da indústria no local. O terceiro eixo aponta para as bases do financiamento, com o capital acumulado principalmente no setor comercial, repetindo um processo que ocorreu também na cidade do Rio de Janeiro, mas para o que concorreu, em Valença, a sua posição privilegiada de contato entre a Corte e Minas Gerais.

De modo geral, as cidades surgidas na região do Vale do Paraíba, como produto da expansão do café, caracterizavam-se por serem, em última análise, centros políticos importan- 
tes de regiões agrárias, "locus" do poder de proprietários de terras e escravos e de seus aliados, os negociantes, sendo importantes para o controle da mão de obra escrava, do comércio - enviando café para o porto e recebendo as mercadorias necessárias - e as grandes decisões políticas locais, articulando, no nível municipal, o próprio projeto de Império do Brasil.

Após a abolição, a diversificação da produção, a alteração nas relações de trabalho, o crescimento das propriedades menores, tudo isto criou uma situação diferente, especialmente em função da instalação da indústria e o crescimento do mercado consumidor local, afirmando uma preponderância das relações econômicas na cidade, ainda que mantendo o seu caráter de centro político importante para a região.

Valença não é uma exceção. Ao contrário, seu crescimento industrial reafirma a importância dos grupos ligados ao controle do capital comercial desde o século XIX. Além disso, confirma ainda o papel desempenhado pela ligação da região com Minas Gerais, de onde vieram recursos monetários e trabalhadores, que ajudaram a desenvolver a região.

\section{Referências bibliográficas}

ANDRADE, Ana Maria Ribeiro; LEVY, Maria Bárbara. Fundamentos do sistema bancário no Brasil, 1834-1860. Estudos Econômicos vol. 15, São Paulo: IPE, 1985.

BERNARDES, Lysia M. O Rio de Janeiro e sua região. Rio de Janeiro: IBGE, 1964.

DAMASCENO FERREIRA, Luiz. História de Valença, 1803-1824. Valença: Editora Valença, 1978.

DEAN, Warren. Expansão do Café e Política Brasileira. In: FAUSTO, Boris. História Geral da Civilização Brasileira. Tomo III, vol. 1, Rio de Janeiro: União Editora S.A, 1997.

FERRAZ, José Ricardo. Tecendo Poderes: a industrialização em Valença, RJ. Projeto de Dissertação de Mestrado. Niterói, UFF/PPGH, 2005.

FERREIRA, Marieta de Moraes. A Crise dos Comissários de Café do Rio de Janeiro. Dissertação Mestrado. Niterói, UFF/PPGH, 1977. Ex. mim.

FERREZ, Gilberto. Pioneiros da Cultura do Café na Era da Independência, Louis François Lecesne e seus vizinhos. Rio de Janeiro: Conselho Federal de Cultura, 1978.

FRAGOSO, João Luís R. Sistemas Agrários em Paraíba do Sul (1850-1920). Um estudo de relações não capitalistas de produção. Dissertação de Mestrado. Rio de Janeiro, UFRJ/IFCS, 1983. Ex. mim.

FRIDMAN, Fania. As cidades e o Café. In: VI CONGRESSO BRASILEIRO DE HISTÓRIA ECONÔMICA e $7^{\text {a }}$ CONFERÊNCIA INTERNACIONAL DE HISTÓRIA DE EMPRESAS. Conservatória, 2005. Ex. mim.

FURTADO, Celso. Formação Econômica do Brasil. 14. ed. São Paulo: Nacional, 1976.

GORENDER, Jacob. O Escravismo Colonial. São Paulo: Ática, 1978.

. Gênese e Desenvolvimento do Capitalismo no Campo no Brasil. In: MORAES FILHO, E.; SAES, D.; GORENDER, J.; FORMAN, S. Trabalhadores, sindicatos e política. São Paulo, Global, s/d. 
GUIMARÃES, Paulo Henrique Pentagna. Tecendo Histórias. Belo Horizonte: Liv. Del Rey Editora, 1997.

IANNI, Otávio. Estado e planejamento econômico no Brasil. Rio de Janeiro: Civilização Brasileira, 1977.

IORIO, Leoni. Valença de ontem e hoje - subsídios para a história do município de Marquês de Valença. Juiz de Fora: Companhia Dias Cardoso, 1953.

LAMEGO, Alberto. O Homem e a Serra. Rio de Janeiro: IBGE, 1963.

LEITHOLD T. Von e RANGO, L. Von. O Rio de Janeiro visto por dois prussianos em 1819. São Paulo: Nacional, 1960.

LENHARO, Alcir. As Tropas da Moderação: o abastecimento da Corte na formação política do Brasil - 1808-1824. São Paulo: Símbolo, 1979.

LEVY, Maria Bárbara. História Financeira do Brasil Colonial. Rio de Janeiro: IBMEC, 1979.

LINHARES, Maria Yedda Leit. História do Abastecimento: uma problemática em questão (1530-1918). Brasília: BINAGRI, 1979.

MACHADO, Humberto Fernandes. Escravos, senhores e café: a crise da cafeicultura escravista do Vale do Paraíba Fluminense, 1860-1888. Niterói: Cromos, 1993.

MARX, Karl. O Capital. Livro, capítulo VI (inédito). São Paulo: Livraria Editora Ciências Humanas, 1978.

MATTOS, Ilmar Rohloff de. O Tempo Saquarema. São Paulo/Brasília: HUCITEC/INL, 1986.

MENDONÇA, Sonia Regina de. Estado e economia no Brasil: opções de desenvolvimento. Rio de Janeiro: Graal, 1986.

- A primeira política de valorização do café e sua vinculação com a economia agrícola do estado do Rio de Janeiro. Dissertação de Mestrado. Niterói, UFF/PPGH, 1977.

MUNIZ, Célia Maria Loureiro. Os Donos da Terra. Um estudo sobre a estrutura fundiária no Vale do Paraíba fluminense no século XIX. Dissertação de Mestrado, UFF/PPGH, 1979. Ex. mim.

OLIVEIRA, Francisco de. A emergência do modo de produção de mercadorias: uma interpretação teórica da economia da República Velha no Brasil (1889-1930). In: . A economia da dependência imperfeita. 3. ed. Rio de Janeiro: Graal, 1980.

OLIVEIRA, Geraldo de Beauclair Mendes de. A Construção Inacabada: a economia brasileira, 1822-1860. Rio de Janeiro: Vício de Leitura, 2001.

PIÑEIRO, Théo Lobarinhas. Crise e resistência no escravismo colonial. Passo Fundo: UPF Editora, 2002.

. Os "Simples Comissários": Negociantes e Política no Império do Brasil. Niterói: EDUFF/PROPRIETAS, 2014.

RIBEYROLLES, Charles de. Brasil pitoresco: história, descrição, viagens, colonização. Instituições. Belo Horizonte: Itatiaia, 1980.

SAINTE HILAIRE, Auguste de. Segunda Viagem do Rio de Janeiro a Minas Gerais e a São Paulo, 1822. São Paulo/Belo Horizonte: EDUSP/Itatiaia, 1974. 
. Viagens pelas Províncias do Rio de Janeiro e Minas Gerais. São Paulo/Belo Horizonte: EDUSP/Itatiaia, 1975.

SARAIVA, Luiz Fernando; PIÑEIRO, Théo L. Compreender o Império: Usos de Gramsci no Brasil do Século XIX. In: ASSIS, Angelo Adriano F. de; SANTOS, João Henrique dos; ALVES, Ronaldo Sávio Paes (Orgs.). Tessituras da Memória: Ensaios Acerca da Construção e uso de Metodologias na Produção da História. Niterói: Vício de Leitura, 2011. pp. 291-312.

SERENI, Emílio. Los Problemas Teoricos y Metodológicos. In: . Agricultura y Desarrollo del Capitalismo. Madrid: Alber Corazón Ed., 1974.

SILVA, Eduardo. Barões e Escravidão. Rio de Janeiro/Brasília: Nova Fronteira/INL, 1984.

SPIX, Johan Baptist; MARTIUS, Karl Friedrich Von. Viagem pelo Brasil. Rio de Janeiro: Melhoramentos, 1975.

STEIN, Stanley. Grandeza e Decadência do Café no Vale do Paraíba. São Paulo: Brasiliense, 1961.

VILLELA, Aníbal; SUZIGAN, Wilson. Política de governo e crescimento da economia brasileira. Rio de Janeiro: IPEA, 1975.

ZERRITY, Arrigo. A lavoura fluminense. Jornal do Commercio, 12/04/1895. 